\title{
"Filling the maize basket" supports crop diversity and quality of household diet in Malawi
}

\author{
Sieglinde S. Snapp • Monica Fisher
}

Received: 5 August 2014 / Accepted: 25 November 2014 / Published online: 21 December 2014

(C) The Author(s) 2014. This article is published with open access at Springerlink.com

\begin{abstract}
Food security and dietary quality are broadly supported development goals, yet few studies have addressed how agricultural subsidy policies and promotion of modern crop varieties impact smallholder farm production and household diet. Crop intensification through subsidies could have indirect impacts through gains/losses in income and purchasing power, as well as direct influences on local availability. An integrated household survey conducted multiple times in Malawi provided evidence-based insights into the complex interactions between agriculture and nutrition. The nationally representative dataset indicated that agricultural input subsidies did not preclude crop or dietary diversity. Two pathways of subsidy impact appeared to be operating: an association with diversified cropping for a direct influence on available food quality; and an association with adoption of modern maize varieties for an indirect influence through commercialization and income that supports diverse food purchases. Although crop diversity was positively associated with dietary diversity, we found that education, income, market access, and availability of improved storage technologies had higher influence on dietary diversity. Finally, we provide evidence supporting the need for complementary investments in both education and employment creation, particularly for female heads of households.
\end{abstract}

Keywords Subsidies · Mixed cropping · Diet quality · Agro-diversity $\cdot$ Intensification

\footnotetext{
S. S. Snapp

Department of Plant, Soil and Microbial Science, Michigan State University, East Lansing, MI, USA

e-mail: snapp@msu.edu

M. Fisher $(\bowtie)$

CIMMYT, International Maize and Wheat Improvement Center, Mexico, Mexico

e-mail: m.fisher@cgiar.org
}

\section{Introduction}

The complex nexus of agricultural policies and subsidy programs has important consequences for agricultural intensification, crop diversification, and human nutrition. Interventions in rural Africa addressing dietary diversity and food insecurity often fall into two categories. One is focused on income, and promotion of commercial agriculture to support gains in purchasing power (Sahn 1990). The other is centered on the household, supporting on-farm production and local availability to mitigate food insecurity. In support of the latter, there is clearly potential for close linkages between agricultural production and household diet among smallholder farmers who consume a substantial portion of what they grow, although markets and local preferences will mediate these linkages (Immink and Alarcon 1991). Indeed, emerging evidence from household surveys in Southern and Eastern Africa support connections between farm production and family diets. For instance, it was shown that female-headed households in Malawi had increased dietary diversity in the presence of high levels of crop and livestock diversity (Jones et al. 2014). Similar trends were observed between dietary diversity and vegetable production diversity in Tanzania and Kenya (Herforth 2010), and also for smallholder female farmers in Burkina Faso (Savy et al. 2006).

A diverse diet has positive impacts on child nutritional status and other health outcomes in children, although there are counter examples (Arimond et al. 2010; Berti and Jones 2013; Bezner Kerr et al. 2011). In this context, there is need for studies exploring the role of agricultural subsidies, and crops grown, on household food consumption. There is emerging evidence from case studies in Malawi and Niger that agricultural policy, which influences production of cereals, pulses and tubers is an unheralded but persistent factor that negatively influences child nutrition (Cornia et al. 2012). It is then surprising that there is limited research on 
agricultural interventions and policies as they relate to diversification of production, and the associated consequences for human nutrition (Berti and Jones 2013). Links have been made in the literature between agricultural policies that promote reliance on staple cereals, with steady declines in consumption of pulses and other minor, often highly nutritious crops, although causality cannot be ascribed to these trends (Hawkes 2007).

The on-farm production pathway for development includes a focus on modern varieties (MV), and intensification of MV production using sustainable practices (Garnett et al. 2013). But what is not well known is the extent to which adoption of MVs is essential to this pathway, and whether MV uptake is typically associated with a narrowing of farm diversity. Modern varieties have displaced landraces in some well documented cases (e.g., Hammer et al. 1996). However, Brush (1995) makes the case that displacement is location specific, and that there are examples where adoption of MVs has enhanced the number of varieties or species grown, leading to greater crop diversity at field and farm level. In Nepal, for example, MVs of rice were taken up by some farmers in an additive manner, enhancing rather than narrowing genetic diversity on farm (Steele et al. 2009). We note that rice MVs in this case were developed with farmer participation, and involved introgression of landrace germplasm. Further studies in Nepal provided evidence that there has been a narrowing of crop species genetic diversity overall; interestingly, this occurred before the vast majority of MVs were introduced (Witcombe et al. 2011).

Adoption of MVs could influence land allocation to sole crop versus intercrop arrangements, as illustrated by recent policies in Rwanda that require planting of MV maize as sole crops in specific growing seasons and locations (Isaacs 2014; MINIAGRI 2009). In Malawi, maize MVs have also been promoted in conjunction with the recommendation that MVs be grown as sole crops (Letourneau 1995), although on-farm trials have shown MVs to be fully compatible with intercrop production practices (Snapp et al. 2010). To the best of our knowledge, the impact of MV adoption on farm and field level diversity, and consequences for household diet, has not been the subject of previous studies.

In the literature, intensification and diversification are often considered to be mutually exclusive forms of agricultural production. However, there is growing interest in agbiodiversification as a foundation for sustainable intensification (Kremen and Miles 2012; Snapp et al. 2010). An important example of the consequences of conflating simplification and intensification is unfolding in Rwanda. Since 2009 the Rwanda government has enforced sole crop production practices along with use of MVs and input intensification, for selected crops per agro-ecological zone (MINIAGRI 2009). This message has prevailed to the extent that crop diversity and intercropping has fallen drastically in recent years and is no longer found on many smallholder farms (Isaacs 2014). Potentially there could be severe negative consequences for dietary diversity on Rwanda farm households, given the steep reduction in types of crops grown from 9 to 11 down to 3-4. Farmers and civil society have raised the issue of how can farmers access high quality nutritious diets given the limited market access and income constraints on many smallholder farms in the country. The Rwanda agricultural policy was developed in part in response to the Malawi agricultural subsidy experience, and both are being closely observed by agricultural development actors (Isaacs 2014).

There is very limited research conducted on the extent to which cropping system simplification and sole-crop arrangements is a necessary corollary to intensification. Very high levels of plant population density are associated with some forms of intensification, particularly under irrigated agriculture (Chen et al. 2011). By contrast, rainfed agriculture is common across Africa, and intensification consists mainly of increased use of fertilizers and adoption of MVs. Over the last few decades in Malawi there has been a steep trend towards increased sole cropping and specialization that has reduced the number of crops grown on-farm, and the presence of intercropped systems from close to $100 \%$ in the $1960 \mathrm{~s}$, to 30 to $65 \%$ in the 1990 s, depending on the region (Heisey and Smale 1995). Preferential production of fertilizer-responsive crops, which are a subset of all crops, could be one driver of the simplified farming systems seen in Malawi and elsewhere (Crews and Peoples 2004). Adoption of MVs and market oriented production could be other major influences (Witcombe et al. 2011).

An important but indirect influence on agbiodiversification has been postulated to be the goal of smallholder farmers to first 'fill their maize basket'; that is, to ensure sufficient production of the staple food. This was thought to be the major reason underlying the positive association of farm size and pulse diversification in a Malawi household survey (Snapp et al. 2002). In Guatemala, evidence from an 'ex-post' classification of crop diversification patterns and food security in a household survey indicated that crop diversification patterns vary widely within and between regions, including the staple crops produced which varied among maize, wheat and potato (Immink and Alarcon 1991). Income and food security was not related in the Guatemala study, and the one clear trend was that diversification into potato among the smallest scale farms was a risky strategy that often led to negative income. While there are few studies that explore the impact of intensified grain production on crop diversification, adoption of MVs with inputs could in theory promote a food secure environment that supports farmer experimentation with growing other crops, for expanded dietary options.

The overarching research question addressed here is if crop production systems are intensified and simplified, will this 
have negative impacts on dietary diversity? Or, will households enjoy an enhanced ability to purchase higher quality foods than those produced themselves through gains in purchasing power from intensified production. This study used the nationally representative Malawi Integrated Household Survey to assess the consequences for cropping system and dietary diversity of efforts to promote maize intensification and MV adoption through a large-scale agricultural input subsidy program.

\section{Data and variable definitions}

\section{The Integrated Household Survey data}

The source of data was the third Malawi Integrated Household Survey (IHS3) a World Bank Living Standards Measurement Study conducted in 2010/11 by the government of Malawi's National Statistical Office (MNSO 2012). The survey collected information at the village, household, individual, and field levels, and merged these data with geographic data from other sources, using GPS coordinates of the villages and household dwellings. The present analysis included IHS3 data on agricultural production, household demographics, household socioeconomic status, and food consumption; rainfall data from the U.S. National Oceanic and Atmospheric Association (NOAA); information on elevation from the International Food Policy Research Institute; and household distance to the nearest major road (primary and secondary networks), calculated from household GPS coordinates and Malawi's National Roads Authority data (see MNSO 2012 for details). Given the study's research questions, we focused on IHS3 sub-samples of maize fields ( $71 \%$ of cultivated fields) and maize farming households ( $94 \%$ of farm households) in both rural and urban locations. (In the sub-sample of maize farming households, $91 \%$ were rural and $9 \%$ urban.) Agricultural production data in the IHS3 concern the 2008/09 (15\% of observations) and 2009/10 (85\% of observations) agricultural years, while the food consumption data concern 2010 and 2011.

\section{Definitions of the main study variables}

The main variables for this study were subsidized fertilizer coupon receipt, modern maize adoption, crop diversification, and dietary diversity. The government of Malawi implemented the large-scale Farm Input Subsidy Program (FISP) in the 2005/06 cropping season with the official aims of increasing maize production, promoting household food security, and enhancing rural incomes. The program provides approximately $50 \%$ of the farmers in the country with free modern maize and legume seed, and subsidized fertilizer for maize production. The subsidized fertilizer coupon entitles farmers to up to two $50 \mathrm{~kg}$ bags of fertilizer at about $5-10 \%$ of the prevailing market price (Lunduka et al. 2013). The FISP targets the "productive poor" defined as farm households with the land and human resources to use the subsidized inputs, but without the financial capital to purchase inputs at commercial prices. The official targeting criteria for beneficiary selection since 2007/08 is: (1) households headed by a Malawian who owns and currently cultivates land; (2) vulnerable households, including guardians of physically challenged persons, and households headed by females, orphans, and children; and (3) only one beneficiary per household, the household head (MoAFS 2008).

For the study's analyses of how agricultural input subsidies impact technology adoption, crop diversification, and dietary diversity, we used a binary variable indicating that the household received a FISP fertilizer subsidy last year. We did not separately measure the receipt of free maize seed under FISP, because more than $95 \%$ of farmers that received a FISP coupon for free maize seed also received a fertilizer coupon. In addition, the value of the free maize seed was minor relative to the value of the subsidized fertilizer (about $10 \%$ ). The IHS3 data do not include information on receipt of legume seed under FISP, and legume seed coupons were not successfully implemented prior to the 2010 FISP, as indicated by 316 coupons being exchanged for legume seed in 2009 (personal communication in 2014 with Charles Clark, Coordinator of the FISP Logistics Unit during the time period the study concerns.)

Modern maize was defined as hybrid, recycled hybrid, or open pollinated varieties, and was contrasted with local maize varieties. While modern maize varieties are the result of crop science breeding, local varieties are the product of centuries of selection by farmers and the natural environment. The IHS3 data include a variable indicating the maize types grown by farmers on their fields, and this was used to categorize maize as modern or local. We measured crop diversification in two ways: the average number of non-maize crop groups intercropped with maize across a farm household's maize fields and the total number of non-maize crop groups cultivated on the household's farm. The various (non-maize) crops cultivated by Malawi households were aggregated into 10 groups: rice; other cereals (wheat, millet, and sorghum); cassava; potatoes (Irish and sweet); groundnut; beans and pulses (ground bean, bean, soybean, pigeon pea, and pea); horticultural crops (cabbage, rape, pumpkin leaves, okra, tomatoes, and onion); tobacco; cotton; and other minor crops (sunflower, sugarcane, paprika, and other not specified). We did not calculate a crop diversification index, such as the Simpson's Index, which accounts for both species richness and evenness. It was not possible to calculate such indexes with reasonable accuracy using the Malawi IHS3 data due to unavailability of area planted for some crops and intercrops. 
In the IHS3 survey, household dietary data were collected by asking respondents to recall for the last 7 days their household members' food consumption from over 100 different food items. We used these data to calculate two common measures of dietary diversity: the Household Dietary Diversity Score (HDDS) and the Food Consumption Score (FCS). The HDDS is a continuous variable with values from zero to 12. In calculating the HDDS, food items were grouped into 12 different categories and each food group was counted toward the household score if an item from the group was consumed in the last 7 days by a household member (Swindale and Bilinsky 2006). The 12 food groups are cereals; roots and tubers; vegetables; fruits; meat and poultry; eggs; fish and seafood; pulses, legumes, and nuts; milk and milk products; oils and fats; sugar and honey; and miscellaneous (condiments, coffee, and tea).

The FCS is a continuous variable calculated on the basis of the frequency of consumption of nine different food groups consumed by a household's members during the 7 days prior to the survey (UNWFP-VAM 2006). The consumption frequency of the nine food groups was multiplied by an assigned weight, based on the energy, protein, and micronutrient densities of each food group, and the resulting values were summed to obtain the FCS. The nine food groups are main staples (cereals, roots, and tubers); pulses, legumes, and nuts; vegetables; fruits; meat, poultry, eggs, and fish; milk and milk products; sugar and honey; oils and fats; and miscellaneous (condiments, coffee, and tea).

\section{Materials and methods}

Empirical models were developed for investigating the study's research questions. First we assessed the impact of Malawi's FISP on adoption of modern maize and on the diversity of crops grown on farms or in fields. We then examined how, if at all, modern maize cultivation and crop diversity (both on farm and in field) influence household dietary diversity. Measuring the impact of FISP on modern maize cultivation and crop diversification is complicated by the problem of selection bias, because subsidized fertilizer coupons were distributed to recipients in a non-random way. Experiments are the best way to eliminate selection bias, but statistical methods that simulate an experimental design using observational data can reduce such bias.

We used a semiparametric technique, propensity score matching (PSM; Rosenbaum and Rubin 1983), to measure the causal effects of the FISP on modern maize adoption, the number of non-maize crops grown on farm, and the number of maize intercrops. Propensity score matching involves three steps. First, a logit or probit model was used to estimate the propensity score, that is, the probability the household received a subsidized fertilizer coupon. Second, a matching algorithm was chosen that uses the estimated propensity score to match each farm household that received a FISP fertilizer coupon (the treatment group) with one or more farm households with a similar propensity score that did not receive a coupon (the control group). In the third step, differences in the outcome variable (modern maize adoption, number of crops grown on farm, or number of maize intercrops) were calculated for the matched treated and untreated cases, and the average of these differences is the average treatment effect on the treatment group (ATT). In the present case, the ATT represents the impact of the FISP on modern maize cultivation or crop diversification among households that received a fertilizer subsidy.

\section{Estimating the propensity score}

A probit regression model was used to estimate the propensity score for the treatment, i.e., FISP receipt. In the probit model (Eq. 1), the dependent variable $F$ was binary indicating the household received a FISP fertilizer subsidy last year.

$F=\beta_{0}+\beta_{1} Y+\beta_{2} \boldsymbol{H}+\beta_{3} \boldsymbol{L}+\nu$

The first explanatory variable, $Y$, specified the 2008/09 agricultural year, to account for differences in FISP between the two years covered by the IHS3. Vector $\boldsymbol{H}$ denoted characteristics of the household head and the household. As mentioned earlier in the paper, the subsidy program was intended to benefit the productive poor. Village chiefs and Village Development Committees were tasked with identifying the productive poor in their community. Variables indicating the household's level of vulnerability were expected to influence coupon receipt and were therefore included in Eq. 1: gender and age of the household head and the household's wealth position. The wealth level variable was created using principal component analysis (Filmer and Pritchett 2001), based on components reflecting household ownership of physical assets (motorcycle, bicycle, radio, television, refrigerator, mobile phone, and livestock), access to utilities and infrastructure (electricity, main source of drinking water), and housing characteristics (type of wall, floor, and roofing material of the dwelling unit; type of toilet; number of rooms per person).

Household-level factors $\boldsymbol{H}$ also included variables for educational attainment of the household head; size of the household's agricultural landholding; number of household members; and a binary variable for whether or not the household received agricultural information last year from any source, e.g., other farmers, extension officers, electronic media. In addition, vector $\boldsymbol{H}$ included a variable for the number of months the household head was away from the village during 
the previous year, as we hypothesized that with a long absence he or she was less likely to be present to receive a coupon.

To assess whether there were locational differences $\boldsymbol{L}$ in administration of the subsidy program, variables were included in Eq. 1 for the distance $(\mathrm{km})$ to the nearest road and to indicate the household resided in the northern or central region (southern region was reference). We also included a binary variable indicating whether a Member of Parliament (MP) resided in or recently visited the community. Allocation of the subsidy coupons at the regional level was supposed to be based on the number of hectares under cultivation. However, there might have been some political influence on allocation, represented by the MP variable (Ricker-Gilbert and Jayne 2011).

Matching untreated observations with treated observations

The second step in the analysis involved choosing and implementing a matching algorithm. Several matching algorithms are available to match treated and untreated groups of similar propensity scores, but the literature provides little guidance as to which work best (Morgan and Harding 2006). We used nearest neighbor matching (NNM) with replacement, which is simple, relatively unbiased, and widely used by researchers in different fields. Nearest neighbor matching constructs the counterfactual for each treatment case, using the control cases nearest to the treatment case on a unidimensional measure, such as the propensity score. To avoid the very poor matches that can sometimes occur with NNM, we specified a caliper that restricts matches to 0.25 standard deviations of the linear propensity score (Rosenbaum and Rubin 1983). We also used kernel-based matching (KBM), which some analysts contend has important advantages over other matching algorithms (Heckman et al. 1998). For the KBM algorithm, the counterfactual is constructed for each treatment case using all control cases, and each control case is weighted based on its distance from the treatment case.

Calculating the average treatment effect on the treated

The ATT was calculated as the difference for a given outcome variable (modern maize adoption, number of non-maize crops, number of maize intercrops) between treatment vs. control groups.

Measuring the association between modern maize, crop diversification, and dietary diversity

The association between modern maize adoption, crop diversification, and dietary diversity was examined by estimating Eq. 2, where the dependent variable $D$ was alternatively the household dietary diversity score (HDDS) and the food consumption score (FCS).

$$
\begin{aligned}
D= & \delta_{0}+\delta_{1} C+\delta_{2} A+\delta_{3} T+\delta_{4} P+\delta_{5} \boldsymbol{I}+\delta_{6} \boldsymbol{H}+\delta_{7} \boldsymbol{X} \\
& +\delta_{8} \boldsymbol{L}+\delta_{9} Y+\delta_{10} \boldsymbol{S}+v
\end{aligned}
$$

In Eq. 2, $C$ was either the average number of intercrops across a farm household's maize fields or the number of nonmaize crop groups grown on farm. Explanatory variables $A$ and $T$ were, respectively, dichotomous variables indicating modern maize cultivation and tobacco cultivation. Maize and tobacco were included because they are, respectively, Malawi's staple crop and its premiere cash crop. The IHS3 dataset includes a price index $P$ that accounts for spatial and temporal price differences; the index was included because we expected that prices for food and other consumer goods negatively correlates to dietary diversity. Vector $\boldsymbol{I}$ consisted of characteristics of the household head that were posited to influence the demand for dietary diversity: age, gender, and educational attainment. The household socio-economic factors $\boldsymbol{H}$ hypothesized to influence dietary diversity were the number of months the household was food insecure in the previous year; household size and composition (numbers of members of different age and sex groups); farm size (an indicator of food security); dichotomous variables for ownership of cattle, goats/sheep, and poultry; and several variables measuring non-agricultural income in the last year (business profits, a binary variable for whether wage income was earned, and a binary variable for whether the household had nonlabor income). Evidence from several contexts indicates that income has a significantly greater positive effect on child nutrition and household food security when income is controlled by women rather than men (Jones et al. 2014; Fisher et al. 2000; Haddad and Hoddinott 1994). For this reason, we considered separately the effects of business profits on dietary diversity for businesses where the main owner was a female vs. a male household member. We also considered separately the effects of wage work engaged in by female vs. male household members. We were unable to separate male versus female control of nonlabor income, due to the unavailability of this information for remittances from children, the main source of nonlabor income. Likewise we did not include a binary variable indicating whether female adult members had full or joint control of agricultural earnings (with male members). The IHS3 survey did ask respondents who in the household controlled agricultural earnings. Unfortunately, this variable had many missing values and would have resulted in a loss of $25 \%$ of observations.

Vector $\boldsymbol{X}$ denoted variables that represent the household's cost of access to dietary variety, including rural residence, distance to the nearest major road $(\mathrm{km})$, the presence of a 
bus stop in the community, whether or not household members owned a bicycle, whether or not there was a daily market in the community, refrigerator ownership by the household, ownership of a storage house or granary, and the presence of a school feeding program in the community. We included binary variables $\boldsymbol{L}$ for residence in the northern or central region to assess any regional variation in dietary diversity. Variable $Y$ indicated the year the household was interviewed about food consumption (was 2010; reference year was 2011). Dietary diversity should be seasonal, with income and food generally most abundant during the maize post-harvest period (June to August). We therefore included season binary variables $\boldsymbol{S}$ to indicate the season in which the IHS3 food consumption modules were implemented with the sample household: maize pre-planting (September to November), maize planting (December to February), or maize harvest (March to May). The reference category for $\boldsymbol{S}$ was the maize post-harvest period.

\section{Results}

Propensity score for FISP fertilizer subsidy receipt

Table 1 presents goodness-of-fit statistics, marginal effects, and $z$-statistics for the probit model estimating the propensity score for FISP fertilizer subsidy receipt. The calculated Pearson $\chi^{2}$ statistic and the percent correctly classified observations (see bottom of Table 1) suggest our model fits reasonably well. To assess potential multicollinearity problems, variance inflation factors (VIFs) were computed for the independent variables. The highest VIF was 1.25. Multicollinearity does not appear to be a problem. To account for possible heteroscedasticity, a common specification error for crosssectional data, the $z$-statistics reported in the table are based on heteroscedasticity-robust standard errors (White 1980).

Turning to the marginal effects and $z$-statistics in Table 1, findings suggest the program was more generous to households headed by females vs. males $(p<0.05)$, which is in accord with FISP targeting criteria. Model results show the likelihood of fertilizer subsidy receipt was positively related to the age of the household head, perhaps because older farmers had the opportunity to develop strong social connections to their village leaders. Political or social motivations might have influenced identification of beneficiaries by village leaders. Households headed by a more educated individual and those with smaller landholdings were less likely to receive a fertilizer subsidy. Contrary to FISP targeting guidelines, evaluations of FISP for 2006/07 and 2008/09 found that better-off households were targeted under the program (Chibwana et al. 2012; Ricker-Gilbert et al. 2011). We reached the same conclusion for 2009/10: households at the bottom $40 \%$ of the wealth distribution were less likely than better-off households
Table 1 Probit regression for FISP fertilizer subsidy receipt, Malawi Integrated Household Survey (IHS3) 2010/11 ( $n=9291$ households)

\begin{tabular}{lrr}
\hline Explanatory variables & $\begin{array}{l}\text { Marginal } \\
\text { effect }\end{array}$ & $\begin{array}{l}z \text { - } \\
\text { value }\end{array}$ \\
\hline Agricultural year 2008/09 & 0.020 & 1.34 \\
Household-level variables & 0.026 & 1.99 \\
$\quad$ Female household head & 0.003 & 10.06 \\
Age of household head (years) & -0.049 & -3.73 \\
Household head had primary education or higher & 0.028 & 6.68 \\
Agricultural landholding (acres) & -0.053 & -4.65 \\
Wealth poor (bottom 40 \% of wealth-index & & \\
$\quad$ distribution) & 0.053 & 6.13 \\
Number of household members & -0.004 & -5.15 \\
Number of household members squared & 0.057 & 5.00 \\
Agricultural information received last year & 0.002 & 0.37 \\
Number of months head was away last year & & \\
Location variables & 0.002 & 4.73 \\
Distance to nearest road (km) & 0.027 & 1.71 \\
Residence in northern region & -0.041 & -3.31 \\
Residence in central region & 0.016 & 1.32 \\
MP resident or recently visited community & 0.18 & \\
Pearson's goodness-of-fit statistic, prob> $\chi^{2}$ & 59.51 & \\
Percent correctly classified & & \\
\hline & &
\end{tabular}

to receive fertilizer coupons. The difference between average coupon receipt of the poor (50\%) and the "non-poor" (55\%) was modest. However, better-off farmers in the Malawi context remain highly resource constrained.

Number of household members was positively correlated with a household receiving a fertilizer coupon (Table 1). Access to agricultural information had a positive influence on the probability a household received a fertilizer subsidy. Probit results indicate some locational differences in administration of the subsidy program. For example, distance from a household's dwelling unit to the nearest road had a positive association with receipt of a fertilizer coupon. Compared to households in the south, central region households were less likely to receive subsidized fertilizer.

Matching untreated observations with treated observations

The predicted propensity scores were used to match treatment with control cases using NNM and KBM. Prior to calculating the impacts on outcomes (i.e., the ATTs), we investigated some issues of matching quality. First, since the matching procedure uses the propensity score rather than all covariates it has to be checked if the matching procedure was able to balance the distribution of the covariates used to predict the propensity score for both the treatment and the control group (Rosenbaum and Rubin 1983). In an experimental setting, randomization would ensure that the relevant observable and 
unobservable characteristics of the farmers under study are balanced, or equally distributed, between treatment and control groups such that the difference in their mean outcomes correctly estimates the impact of treatment. We examined if our matching procedure simulated an experiment and yielded a balanced distribution of covariates.

There are several procedures to check this balancing condition, all compare the situation before and after matching to check if there remain any differences after conditioning on the propensity score. Where differences are found remedial measures should be taken, such as including quadratic or interaction terms in the estimation of the propensity score (Caliendo and Kopeinig 2008).

One way to assess balance is using paired $t$-tests for differences in covariate means across matched treatment and control cases (Rosenbaum and Rubin 1983). Differences are expected prior to but not after matching. We tested balance for the different treatment variables and different matching algorithms and found statistically significant differences $(p<0.05)$ in the means for the two groups for only one variable: household size. Inclusion of a quadratic term for household size remedied the situation (Table 1). Results of the paired $t$-tests are not shown due to space limitations, but are available upon request.

Balance can also be assessed by re-estimating the propensity score on the matched sample and comparing the pseudo$R^{2}$ before and after matching (Sianesi 2004). The pseudo- $R^{2}$ indicates the explanatory power of the covariates. After matching there should be no systematic differences in the distribution of covariates between treated and untreated, thus the pseudo- $R^{2}$ should be relatively low. A likelihood ratio (LR) test of joint significance of all model covariates can also be used to assess balance. The LR test should not be rejected before, and should be rejected after, matching (Caliendo and Kopeinig 2008). Findings in Table 2, in tandem with the paired $t$-tests discussed earlier, suggest our propensity score specifications were generally quite successful at achieving covariate balance.

It is also important to check the common support condition, i.e. that there is considerable overlap in the predicted propensity scores of the treatment and control groups. Among the FISP fertilizer coupon recipients (treated), the predicted propensity score had a range of $[0.231,0.997]$. For those that did not receive a fertilizer subsidy (untreated), the corresponding range was $[0.241,0.950]$. There is considerable overlap in common support. The reported ranges of the propensity scores were for the case of modern maize adoption, but the corresponding figures for number of crops and average number of intercrops were very similar (data not shown).

The ATT is defined only in the region of common support. Observations that fall outside this region are discarded and for these individuals the treatment effect is not estimated. When the proportion of observations discarded is small this poses few estimation problems, but if this proportion is large it may be questioned whether or not the estimated effect on the remaining individuals is representative (Bryson et al. 2002). For modern maize adoption, two treated observations, representing $0.02 \%$ of the sample, were off support, i.e., adequate untreated matches could not be found, and were discarded when calculating the ATT. For number of nonmaize crops grown on farm, two off-support treated observations ( $0.02 \%$ of sample) were discarded. For average number of maize intercrops across a farmer's fields, two off-support treated observations $(0.02 \%$ of sample $)$ were discarded.

The average treatment effect on the treated (ATT)

Table 3 presents the estimated differences in outcomes among farm households who did and did not receive a FISP fertilizer coupon in the previous year. For the three outcome variables, measured impacts were quite robust across different matching algorithms, particularly for the case of modern maize adoption. The measured impacts of the FISP were quite large. Receipt of a FISP was associated with increased cultivation of modern maize of about 0.135 percentage points, or $27 \%$. (In calculating percentage from percentage point difference, the numerator is Impact (ATT) and the denominator is the POM for the Controls.) Receipt of a FISP was also associated with significant increases in on-farm $(27 \%)$ and in-field $(30 \%)$ crop diversification.

It would seem plausible that the positive association observed between subsidy coupon receipt and the diversity of crops grown is partly explained by the inclusion since 2007/08 of free seed for grain legumes as a voucher option in the FISP (Lunduka et al. 2013); however, the program of legume seed distribution was implemented at a very small scale up to 2010 . It was reported that the number of legume seed vouchers redeemed was less than $1 \%$ relative to maize seed (Charles Clark, personal communication 2014). We also note that some of the FISP fertilizer received by a farmer may have been used to cultivate other (i.e., non-maize) fertilizer-responsive crops such as tobacco.

The relationship between modern maize cultivation, crop diversification, and dietary diversity

Findings for the determinants of dietary diversity are presented in Table 4 (HDDS) and Table 5 (FCS). Goodness-of-fit statistics are presented at the bottom of each table: the Pearson $\chi^{2}$ statistic for the Poisson models (Table 4) and the $R^{2}$ statistic for the linear regression models (Table 5). Multicollinearity does not appear to be a problem with the explanatory variables as the calculated VIFs had a mean of 1.5 and the highest VIF (for the price index) was 3.18. The $z$-statistics reported in the tables are based on heteroscedasticity-robust standard errors (White 1980). Most of the explanatory variables were statistically 
Table 2 Matching quality indicators. Parameter estimates from propensity score matching where propensity scores were predicted from the model in Table 1. Matching algorithms used were nearest neighbor matching (NNM) with the one and five nearest neighbors and the caliper set to 0.25 standard deviations of the linear propensity score, and kernelbased matching $(\mathrm{KBM})$ with the Epanechikov kernel type and bandwidths of 0.03 and 0.06

\begin{tabular}{|c|c|c|c|c|c|c|c|}
\hline Outcome variable & $\begin{array}{l}\text { Matching } \\
\text { algorithm }\end{array}$ & $\begin{array}{l}\text { Pseudo- } R^{2} \\
\text { before matching }\end{array}$ & $\begin{array}{l}\text { Pseudo- } R^{2} \\
\text { after matching }\end{array}$ & $\begin{array}{l}\text { LR } X^{2} \text { ( } p \text {-value) } \\
\text { before } \\
\text { matching }\end{array}$ & $\begin{array}{l}\operatorname{LR} X^{2} \text { ( } p \text {-value) } \\
\text { after } \\
\text { matching }\end{array}$ & $\begin{array}{l}\text { Mean bias } \\
\text { before } \\
\text { matching }\end{array}$ & $\begin{array}{l}\text { Mean bias } \\
\text { after } \\
\text { matching }\end{array}$ \\
\hline Adoption & NNM (1) & 0.030 & 0.001 & $389.01(0.000)$ & $14.90(0.385)$ & 10.0 & 1.8 \\
\hline Adoption & NNM (5) & 0.030 & 0.000 & $389.01(0.000)$ & $3.72(0.997)$ & 10.0 & 0.9 \\
\hline Adoption & KBM (0.03) & 0.030 & 0.000 & $389.01(0.000)$ & $6.33(0.957)$ & 10.0 & 1.0 \\
\hline Adoption & KBM (0.06) & 0.030 & 0.004 & $389.01(0.000)$ & $48.86(0.000)$ & 10.0 & 2.6 \\
\hline Number crops & NNM (1) & 0.030 & 0.001 & $387.53(0.000)$ & $8.04(0.887)$ & 9.9 & 1.2 \\
\hline Number crops & NNM (5) & 0.030 & 0.000 & $387.53(0.000)$ & $1.63(1.000)$ & 9.9 & 0.4 \\
\hline Number crops & KBM $(0.03)$ & 0.030 & 0.000 & $387.53(0.000)$ & $1.36(1.000)$ & 9.9 & 0.5 \\
\hline Number crops & KBM (0.06) & 0.030 & 0.000 & $387.53(0.000)$ & $2.95(0.999)$ & 9.9 & 0.7 \\
\hline Intercrops & NNM (1) & 0.030 & 0.001 & $387.53(0.000)$ & $8.69(0.850)$ & 9.9 & 1.3 \\
\hline Intercrops & NNM (5) & 0.030 & 0.000 & $387.53(0.000)$ & $1.55(1.000)$ & 9.9 & 0.4 \\
\hline Intercrops & KBM (0.03) & 0.030 & 0.000 & $387.53(0.000)$ & $6.42(0.955)$ & 10.0 & 0.6 \\
\hline Intercrops & KBM (0.06) & 0.030 & 0.004 & $387.53(0.000)$ & $48.88(0.000)$ & 9.9 & 2.6 \\
\hline
\end{tabular}

significant at standard test levels. Findings generally conformed to prior expectations, based on review of relevant literature. The results indicate that households with a female head had lower dietary diversity than households headed by a male, in contradiction to other studies (Jones et al. 2014; Haddad and Hoddinott 1994). But consistent with these previous studies, our findings for employment and business income suggest that income in the hands of women had a greater benefit to household dietary diversity than income controlled by men. We expect our finding for the female headship variable reflects that female-headed households are on average poorer than maleheaded households and therefore less able to afford dietary diversity. While we have included variables for education, income, farm size, and livestock holdings, it is quite likely that the regressions do not fully control for differences in economic well-being between female- and male-headed households.

Education imparts greater knowledge regarding food choices and nutrition. The relatively large magnitude of the parameter estimates for the education variable suggests it is a crucial factor for increasing dietary diversity in Malawi, as
Table 3 The impact of FISP fertilizer subsidy receipt on modern maize adoption and crop diversification, Malawi IHS3 2010/11. Parameter estimates from propensity score matching where propensity scores were predicted from the model in Table 1. Matching algorithms used were NNM with the one and five nearest neighbors and the caliper set to 0.25 standard deviations of the linear propensity score, and KBM with the Epanechikov kernel type and bandwidths of 0.03 and 0.06

\footnotetext{
${ }^{1}$ Potential outcome means ${ }^{2 * * *} p<0.01$
}

\begin{tabular}{|c|c|c|c|}
\hline & $\begin{array}{l}\text { Modern maize } \\
\text { adoption }\end{array}$ & $\begin{array}{l}\text { Number of } \\
\text { non-maize } \\
\text { crops grown }\end{array}$ & $\begin{array}{l}\text { Average number } \\
\text { of maize intercrops }\end{array}$ \\
\hline \multicolumn{4}{|l|}{ NNM (1) } \\
\hline POMs Treated ${ }^{1}$ & 0.630 & 1.551 & 0.713 \\
\hline POMs Controls & 0.495 & 1.217 & 0.549 \\
\hline $\operatorname{Impact}(\mathrm{ATT})^{2}$ & ${ }^{* * *} 0.135$ & *** 0.334 & ${ }^{* * *} 0.164$ \\
\hline \multicolumn{4}{|l|}{ NNM (5) } \\
\hline POMs Treated & 0.630 & 1.551 & 0.713 \\
\hline POMs Controls & 0.498 & 1.235 & 0.560 \\
\hline Impact (ATT) & ${ }^{* * *} 0.132$ & ${ }^{* * * *} 0.316$ & ${ }^{* * *} 0.153$ \\
\hline \multicolumn{4}{|l|}{$\mathrm{KBM}(0.03)$} \\
\hline POMs Treated & 0.630 & 1.551 & 0.713 \\
\hline POMs Controls & 0.501 & 1.244 & 0.574 \\
\hline Impact (ATT) & ${ }^{* * *} 0.129$ & ${ }^{* * *} 0.306$ & ${ }^{* * *} 0.139$ \\
\hline \multicolumn{4}{|l|}{ KBM $(0.06)$} \\
\hline POMs Treated & 0.630 & 1.551 & 0.713 \\
\hline POMs Controls & 0.501 & 1.225 & 0.572 \\
\hline Impact (ATT) & *** 0.129 & *** 0.326 & ${ }^{* * *} 0.141$ \\
\hline
\end{tabular}


Table 4 Poisson regression for household dietary diversity score (HDDS), Malawi IHS3 2010/11 ( $n=9189$ )

Explanatory variable

Constant
Crop diversification (field or farm level) last year
Average number of maize intercrops across fie

Average number of maize intercrops across fields

Number of non-maize crops grown on farm

Grew modern maize last year

Grew tobacco last year

Price index

Characteristics of the household head

Age (years)

Female

Completed primary school

Household characteristics

Number of months food insecure last year

Number of adults (15-64 years)

Number of children (6-14 years)

Number of young children ( $<6$ years)

Number of elders ( 65 years + )

Farm size (acres)

Number of cattle owned

Number of goats/sheep owned

Number of poultry owned

Female business profit (1000 MK) last year

Male business profit (1000 MK) last year

Female wage employment last year

Male wage employment last year

Non-labor income last year

Costs of access

Rural residence

Distance to nearest road (km)

Bus stop in community

Bicycle ownership

Daily market in community

Refrigerator owned

Storage house or granary owned

School feeding in community

Location variables

Residence in northern region

Residence in central region

Season and year of the interview

Interviewed in 2010

Interviewed in Sept-Nov

Interviewed in Dec-Feb

Interviewed in Mar-May

Pearson's goodness-of-fit statistic, prob $>\chi^{2}$
Model 1 (average number

maize intercrops across fields)

IRR

7.815

1.019

1.041

1.004

1.001

0.998

0.966

1.066

0.981

1.003

0.995

0.994

0.998

1.010

1.032

1.021

1.052

1.084

1.077

1.077

1.050

1.068

0.924

0.997

1.018

1.050

1.054

1.055

1.016

1.020

0.989

0.996

1.066

0.976

0.969

0.943

1.00

11.71
Model 2 (number non-maize crops grown on farm)

\begin{tabular}{lc}
\hline IRR & z-value \\
\hline 7.765 & 43.59
\end{tabular}

43.86

6.10

$\begin{array}{rrr}7.94 & 1.019 & 8.40 \\ 0.49 & 1.038 & 7.52 \\ 1.58 & 0.988 & -1.58 \\ & 1.001 & 1.82 \\ -10.96 & & \\ -5.09 & 0.997 & -11.02 \\ 11.28 & 0.965 & -5.13 \\ & 1.065 & 11.18\end{array}$

$-14.67$

0.981

$-14.67$

1.43

1.003

1.34

$-2.32$

0.995

$-2.40$

$-1.94$

0.994

$-2.09$

$-0.27$

0.998

$-0.26$

5.04

1.008

4.16

2.92

1.030

2.74

3.38

1.019

3.13

9.02

9.90

10.83

6.96

7.65

11.64

1.051

1.067

$-9.89$

$-9.35$

0.919

-9.89
-10.25

$-10.53$

0.997

-10.25
3.50

1.019

3.50

9.38

1.049

9.18

1.056

9.47

1.057

4.42

1.016

2.28

2.26

1.018

3.19

$-1.34$

0.982

$-2.23$

$-0.53$

0.993

$-0.99$

7.04

1.063

6.81

$-3.79$

0.977

$-3.57$

$-3.54$

0.971

$-3.39$

$-8.12$

0.943

$-8.10$

1.00 
Table 5 Ordinary least squares regression for food consumption score (FCS), Malawi IHS3 2010/11 ( $n=9210)$

\begin{tabular}{|c|c|c|c|c|}
\hline \multirow[t]{2}{*}{ Explanatory variable } & \multicolumn{2}{|c|}{$\begin{array}{l}\text { Model } 1 \text { (average number } \\
\text { maize intercrops across fields) }\end{array}$} & \multicolumn{2}{|c|}{$\begin{array}{l}\text { Model } 2 \text { (number non-maize } \\
\text { crops grown on farm) }\end{array}$} \\
\hline & Coefficient & t-value & Coefficient & t-value \\
\hline Constant & 48.650 & 14.66 & 48.007 & 14.44 \\
\hline \multicolumn{5}{|l|}{ Crop diversification (field or farm level) last year } \\
\hline Average number maize intercrops across fields & -0.189 & -0.94 & & \\
\hline Number non-maize crops grown last year & & & 0.333 & 2.17 \\
\hline Grew modern maize last year & 1.845 & 5.99 & 1.827 & 5.94 \\
\hline Grew tobacco last year & -0.025 & -0.05 & -0.217 & -0.43 \\
\hline Price index & -0.012 & -0.37 & -0.010 & -0.31 \\
\hline \multicolumn{5}{|l|}{ Characteristics of the household head } \\
\hline Age (years) & -0.079 & -5.72 & -0.078 & -5.72 \\
\hline Female & -1.776 & -4.51 & -1.802 & -4.57 \\
\hline Completed primary school & 1.533 & 2.84 & 1.542 & 2.86 \\
\hline \multicolumn{5}{|l|}{ Household characteristics } \\
\hline Number of months food insecure last year & -1.139 & -16.44 & -1.142 & -16.47 \\
\hline Number of adults (15-64 years) & 0.195 & 1.27 & 0.198 & 1.29 \\
\hline Number of children (6-14 years) & -0.394 & -3.03 & -0.396 & -3.04 \\
\hline Number of young children ( $<6$ years) & -0.277 & -1.49 & -0.282 & -1.52 \\
\hline Number of elders ( 65 years + ) & -0.247 & -0.53 & -0.238 & -0.51 \\
\hline Farm size (acres) & 0.760 & 5.65 & 0.721 & 5.37 \\
\hline Number of cattle owned & 3.513 & 3.90 & 3.520 & 3.91 \\
\hline Number of goats/sheep owned & 1.004 & 2.51 & 0.955 & 2.38 \\
\hline Number of poultry owned & 1.998 & 5.79 & 1.889 & 5.43 \\
\hline Female business profit (1000 MK) last year & 3.523 & 5.55 & 3.447 & 5.43 \\
\hline Male business profit (1000 MK) last year & 4.438 & 8.37 & 4.398 & 8.29 \\
\hline Female wage employment last year & 4.846 & 5.08 & 4.822 & 5.05 \\
\hline Male wage employment last year & 4.215 & 8.19 & 4.178 & 8.12 \\
\hline Non-labor income last year & 3.511 & 9.12 & 3.457 & 8.99 \\
\hline \multicolumn{5}{|l|}{ Costs of access } \\
\hline Rural residence & -4.302 & -5.29 & -4.465 & -5.47 \\
\hline Distance to nearest road $(\mathrm{km})$ & -0.127 & -8.58 & -0.123 & -8.30 \\
\hline Bus stop in community & 1.292 & 3.83 & 1.350 & 4.00 \\
\hline Number of bicycles owned & 3.020 & 8.80 & 3.021 & 8.80 \\
\hline Daily market in community & 3.949 & 10.03 & 4.022 & 10.21 \\
\hline Refrigerator owned & 15.633 & 9.97 & 15.807 & 10.08 \\
\hline Storage house or granary owned & 0.847 & 1.85 & 0.811 & 1.77 \\
\hline School feeding in community & 0.467 & 1.20 & 0.371 & 0.95 \\
\hline \multicolumn{5}{|l|}{ Location variables } \\
\hline Residence in northern region & -1.526 & -2.57 & -1.274 & -2.20 \\
\hline Residence in central region & -1.387 & -2.85 & -1.033 & -2.18 \\
\hline \multicolumn{5}{|l|}{ Season and year of the interview } \\
\hline Interviewed in 2010 & 3.461 & 5.83 & 3.431 & 5.79 \\
\hline Interviewed in Sept-Nov & -0.437 & -0.96 & -0.425 & -0.94 \\
\hline Interviewed in Dec-Feb & 0.077 & 0.13 & 0.097 & 0.17 \\
\hline Interviewed in Mar-May & -4.035 & -8.18 & -4.010 & -8.13 \\
\hline$R^{2}$ statistic & 0.24 & & 0.24 & \\
\hline
\end{tabular}


was found for Tanzania (Abdulai and Aubert 2004) and Bangladesh (Rashid et al. 2011). The number of months the household was food insecure in the past year had a negative association with dietary diversity. Household composition had some, albeit a small, influence on dietary diversity: HDDS and FCS decreased with the number of child members.

Lower costs of accessing a variety of foods was also associated with higher dietary diversity in Malawi, as indicated by the parameter estimates for rural location, school feeding program in the community, proximity to a major road, transport availability (i.e., having a bus stop in the community and household bicycle ownership; Liu et al. 2013; Torheim et al. 2004). Access to storage facilities, such as ownership of a refrigerator, storage house, or granary, also mattered importantly. Perhaps consumers who own a refrigerator can buy a large quantity or variety of food, smooth consumption, and reduce shopping frequency (Liu et al. 2013). Our findings also reveal that dietary diversity is highly seasonal in Malawi, with household dietary diversity peaking in the maize post-harvest period (June through August) when food is relatively abundant. Results also show that dietary diversity was lower in 2011 than in 2010.

Increasing household income is often argued to be a key way to improve household dietary diversity, and there is much research supporting this hypothesis (Abdulai and Aubert 2004; Ecker and Qaim 2011; Rashid et al. 2011; Theil and Finke 1983). The regressions explored how three sources of nonagricultural income relate, if at all, to diet quality. We found that dietary diversity was higher where households engaged in wage employment, earned business income, and had nonlabor income in the last year (Tables 4 and 5). Furthermore, income controlled by female household members often had a stronger positive association with dietary diversity than income controlled by male members (Jones et al. 2014; Haddad and Hoddinott 1994).

Agriculture can influence dietary quality in farm households in several ways (Gillespie et al. 2012). For example, increased income from agricultural commercialization can enable households to purchase different and higher quality foods than they produce themselves. Results in Tables 4 and 5 show adoption of modern maize was associated with higher dietary diversity in Malawi, which might reflect that some of the increased maize output was sold and earnings were used to buy higher quality food. Several other studies found that technological change and commercialization were accompanied by food consumption improvements among adopting households (Sahn et al. 1994; Von Braun and Kennedy 1994); but how commercialization impacts diets and nutrition is not determinate and depends on complex relationships at household and intra-household levels (Von Braun and Kennedy 1994). There is evidence that tobacco cultivation leads to higher income of smallholder tobacco farmers in Malawi (Orr 2000), but our results indicate no statistically significant association between growing tobacco and dietary diversity. Orr (2000) showed for Malawi that compared to farm households not growing tobacco, tobacco growers had higher average expenditure on nonfood items, but food expenditure per capita was essentially the same.

Agriculture also influences dietary quality in farm households where households produce a variety of crops or livestock, and they consume at least some of their production. Similar to other recent research (e.g., Bhagowalia et al. 2012; Thorne-Lyman et al. 2010), our findings show that livestock diversity was positively associated with dietary diversity. Likewise, results indicate a positive link between crop diversification and dietary diversity, controlling for other important variables (Jones et al. 2014). Specifically, as indicated by the 1.019 IRR in Table 4, a one unit increase in the average number of intercrops on a farm household's maize fields was associated with a $2 \%$ increase in the HDDS. And a one crop increase in the number of non-maize crops grown on farm was associated with a $2 \%$ increase in the HDDS. To understand the importance of the number of non-maize crops variable in explaining the FCS (Table 5) we divided the unstandardized coefficient by 46.65 , the predicted value of the FCS. The parameter estimate suggests that increasing the number of non-maize crops grown on farm by one was associated with about a $1 \%$ increase in the FCS.

\section{Discussion}

Importantly, our results from nationally representative data for Malawi indicate that agricultural input subsidies do not preclude crop or dietary diversity. Indeed, the findings are consistent with a net positive effect of agricultural input subsidies on households' quality of food consumption. One pathway from subsidies to improved dietary diversity is that subsidies had a positive association with crop diversification which was positively correlated to dietary diversity. A second channel from agricultural input subsidies to better quality diets identified in this study is that the FISP subsidies promoted adoption of maize MVs while the growing of modern maize was associated with higher dietary diversity, probably the result of maize commercialization and the use of some of the earned income to buy different, higher quality foods. These results are in keeping with long-term stated policies of the Malawi government, and with the recent achievement of FISP that promoted improved access to seed of four food legumes (Mayer 2014). Interestingly, the gains in crop diversification documented here were from 2009/10, before the FISP subsidies included diverse crop seeds (this was not achieved until 2012; Charles Clark, personal communication 2014). This indicates the importance of considering indirect pathways, such as subsidies and adoption of MVs, as a means to "fill the maize basket", which may have freed up farmers to grow more mixed crops. 
Over time we expect to see further changes in farm diversity, as intensification pathways that involve high population densities of sole crops are being promoted both within the region (Rwanda) and beyond (China) (Chen et al. 2011; Isaacs 2014). Further, there is evidence in earlier reports that crop diversity is declining rapidly in Malawi, pointing out the role of multiple factors driving crop choice (Heisey and Smale 1995). The evidence presented here illustrates that MV adoption is fully compatible with mixed cropping, and with dietary diversity; this is suggestive that agricultural intensification pathways can be pursued that take into account the need for on-farm production of diverse food products in an environment with poor market infrastructure.

In contrast to our findings, a recent study in two Malawi districts found that receipt of agricultural input subsidies under FISP was associated with crop simplification: on average, sampled farmers who received coupons allocated $16 \%$ more land to maize than those who did not. Furthermore, the increased share of a household's farmland allocated to maize occurred at the expense of other crops (legumes, cassava, and sweet potato), which were allocated $21 \%$ less land, on average (Chibwana et al. 2012). The authors of that paper stated the need for additional research using nationally representative data before drawing conclusions on the impacts of FISP. Kankwamba et al. (2012), using the nationally representative IHS3 dataset, reached the same conclusion as us, that FISP coupon receipt was associated with crop diversification. Holden and Lunduka (2010) using a Malawi panel dataset for 2006, 2007, and 2009, similarly found a positive association between agricultural input subsidies and crop diversification.

Although our results are consistent with a role for subsidies, several other factors were found to be as or more important in increasing dietary diversity. Increased income from non-agricultural and agricultural sources was critical to dietary diversity, but income was not the most important determinant, and income under the control of women had greater positive impact on household dietary diversity. Further, this survey showed that both livestock and crop production diversity were important to household quality of consumption. Variables measuring costs of accessing a variety of foods were strongly correlated to dietary diversity. Education of the household head was also essential to dietary diversity. We note the importance for female headship in particular. Research in Malawi has previously highlighted the role of women in controlling expenditure related to child diet, providing a clear logic for the role of education among female household heads in supporting high quality household diet (Kennedy and Peters 1992). There are contradictory findings, as earlier research in Ivory Coast found that education of the father was a negative factor on child nutritional status and education of the mother was a neutral factor (Sahn 1990); whereas another study in Ivory Coast found evidence that educated women preferentially invest in child nutrition (Haddad and Hoddinott 1994). Our results lend strong support for a beneficial effect of education on household diet.

Overall, our findings have policy implications for agricultural development initiatives that rely on subsidies to improve access to fertilizer and MV seeds. Agricultural subsidies can have substantial budgetary implications for public investment options. Fertilizer subsidies have cost the Malawi government from 5 to $16 \%$ of GDP in recent years (Chirwa and Dorward 2013), and similar subsidy programs are underway throughout the region. It is encouraging that we observed compatibility of costly government agricultural subsidy programs with crop diversification and dietary diversification. Specifically, the link to crop diversification may then promote environmental benefits such as pest control services and reduced fertilizer requirements (Letourneau 1995; Snapp et al. 2010). However, to support gains in dietary diversity, there is evidence of the need for complementary investments in education, particularly of female heads of households, and improvement in opportunities for women to earn income. The costs of access to food, as measured by infrastructure, transport, and food storage facilities, were all highly influential and we contend these will require attention if nutritional goals are to be achieved such as enhanced dietary quality among vulnerable populations.

Acknowledgments We would like to thank Danielle Zoellner for outstanding editorial assistance. This research was supported by the USAID Africa RISING program.

Conflict interest The authors declare that they have no conflict of interest.

Open Access This article is distributed under the terms of the Creative Commons Attribution License which permits any use, distribution, and reproduction in any medium, provided the original author(s) and the source are credited.

\section{References}

Abdulai, A., \& Aubert, D. (2004). A cross-section analysis of household demand for food and nutrients in Tanzania. Agricultural Economics, 31(1), 67-79. doi:10.1016/j.agecon.2003.03.001.

Arimond, M., Hawkes, C., Ruel, M. T., Sifri, Z., Berti, P. R., Leroy, J. L., et al. (2010). Agricultural interventions and nutrition: Lessons from the past and new evidence. In B. Thompson \& L. Amoroso (Eds.), Combating micronutrient deficiencies: Food-based approaches. Rome: Food and Agriculture Organization.

Berti, P. R., \& Jones, A. D. (2013). Biodiversity's contribution to dietary diversity: Magnitude, meaning and measurement. In J. Franzo, D. Hunter, T. Borelli, \& F. Mattei (Eds.), Diversifying food and diets: Agricultural biodiversity to improve nutrition and health (pp. 186206). Routledge: Earthscan.

Bezner Kerr, R., Berti, P. R., \& Shumba, L. (2011). Effects of a participatory agriculture and nutrition education project on child growth in 
northern Malawi. Public Health Nutrition, 14(8), 1466-1472. doi: 10.1017/S1368980010002545.

Bhagowalia, P., Headey, D., \& Kadiyala, S. (2012). Agriculture, income, and nutrition linkages in India. Insights from a nationally representative survey. Washington, DC: International Food Policy Research Institute.

Brush, S. B. (1995). In-situ conservation of landraces in centers of crop diversity. Crop Science, 35(2), 346-354.

Bryson, A., Dorsett, R., \& Purdon, S. (2002). The use of propensity score matching in the evaluation of labour market policies. London: Policy Studies Institute and National Centre for Social Research, Department of Work and Pensions.

Caliendo, M., \& Kopeinig, S. (2008). Some practical guidance for the implementation of propensity score matching. Journal of Economic Surveys, 22(1), 31-72. doi:10.1111/j.1467-6419.2007.00527.x.

Chen, X. P., Cui, Z. L., Vitousek, P. M., Cassman, K. G., Matson, P. A., Bai, J. S., et al. (2011). Integrated soil-crop system management for food security. Proceedings of the National Academy of Sciences of the United States of America, 108(16), 6399-6404. doi:10.1073/ pnas.1101419108.

Chibwana, C., Fisher, M., \& Shively, G. (2012). Cropland allocation effects of agricultural input subsidies in Malawi. World Development, 40(1), 124-133.

Chirwa, E., \& Dorward, A. (2013). Agricultural input subsidies: The recent malawi experience. Oxford: Oxford University Press.

Cornia, G. A., Deotti, L., \& Sassi, M. (2012). Food price volatility over the last decade in Niger and Malawi: Extent, sources and impact on child malnutrition. Addis Ababa: Regional Bureau for Africa, United Nations Development Programme.

Crews, T. E., \& Peoples, M. B. (2004). Legume versus fertilizer sources of nitrogen: ecological tradeoffs and human needs. Agriculture, Ecosystems \& Environment, 102(3), 279-297. doi:10.1016/j.agee. 2003.09.018.

Ecker, O., \& Qaim, M. (2011). Analyzing nutritional impacts of policies: an empirical study for Malawi. World Development, 39(3), 412-428. doi:10.1016/j.worlddev.2010.08.002.

Filmer, D., \& Pritchett, L. H. (2001). Estimating wealth effects without expenditure data - or tears: an application to educational enrollments in states of India. Demography, 38(1), 115-132. doi:10.2307/3088292.

Fisher, M. G., Warner, R. L., \& Masters, W. A. (2000). Gender and agricultural change: crop-livestock integration in Senegal. Society \& Natural Resources, 13(3), 203-222. doi:10.1080/089419200279063.

Garnett, T., Appleby, M. C., Balmford, A., Bateman, I. J., Benton, T. G., Bloomer, P., et al. (2013). Sustainable intensification in agriculture: premises and policies. Science, 341(6141), 33-34. doi:10.1126/ science. 1234485.

Gillespie, S., Harris, J., \& Kadiyala, S. (2012). The agriculture-nutrition disconnect in India. What do we know? Washington, DC: International Food Policy Research Institute.

Haddad, L., \& Hoddinott, J. (1994). Women's income and boy-girl anthropometric status in the Cǒte d'Ivoire. World Development, 22(4), 543-553. doi:10.1016/0305-750x(94)90110-4.

Hammer, K., Knupffer, H., Xhuveli, L., \& Perrino, P. (1996). Estimating genetic erosion in landraces - two case studies. Genetic Resources and Crop Evolution, 43(4), 329-336. doi:10.1007/bf00132952.

Hawkes, C. (2007). Promoting healthy diets and tackling obesity and diet-related chronic diseases: what are the agricultural policy levers? Food and Nutrition Bulletin, 28(2), S312-S322.

Heckman, J. J., Ichimura, H., \& Todd, P. (1998). Matching as an econometric evaluation estimator. Review of Economic Studies, 65(2), 261-294. doi:10.1111/1467-937x.00044.

Heisey, P. W., \& Smale, M. (1995). Maize Technology in Malawi: A green revolution in the making? (p. 68). Mexico: CIMMYT.

Herforth, A. (2010). Promotion of traditional African vegetables in Kenya and Tanzania: A case study of an intervention representing emerging imperatives in global nutrition. (PhD Dissertation), Cornell University, Cornell, NY, USA.
Holden, S. T., \& Lunduka, R. (2010). Too poor to be efficient? Impacts of the targeted fertilizer subsidy program in Malawi on farm plot level input use, crop choice and land productivity. As: Norwegian University of Life Sciences.

Immink, M. D. C., \& Alarcon, J. A. (1991). Household food security, nutrition and crop diversification among smallholder farmers in the highlands of Guatemala. Ecology of Food and Nutrition, 25(4), 287-305. doi:10.1080/03670244.1991.9991177.

Isaacs, K. (2014). Rediscovering the value of diversity in Rwanda: participatory variety selection and genotype by cropping system interactions in bean and maize cropping systems. ( $\mathrm{PhD}$ Dissertation), Michigan State University, East Lansing, MI.

Jones, A. D., Shrinivas, A., \& Bezner-Kerr, R. (2014). Farm production diversity is associated with greater household dietary diversity in Malawi: findings from nationally representative data. Food Policy, 46, 1-12. doi:10.1016/j.foodpol.2014.02.001.

Kankwamba, H., Mapila, M. A. J., \& Pauw, K. (2012). Determinants and spatiotemporal dimensions of crop diversification in Malawi, IFPRI Project Report. Lilongwe, Malawi: Malawi Strategic Support Program, IFPRI.

Kennedy, E., \& Peters, P. (1992). Household food security and child nutrition - the interaction of income and gender of household head. World Development, 20(8), 1077-1085. doi:10.1016/0305-750x(92)90001-c.

Kremen, C., \& Miles, A. (2012). Ecosystem services in biologically diversified versus conventional farming systems: Benefits, externalities, and trade-offs. Ecology and Society, 17(4). doi: 10.5751/es-05035-170440

Letourneau, D. K. (1995). Associational susceptibility - effects of cropping pattern and fertilizer on Malawian bean fly levels. Ecological Applications, 5(3), 823-829. doi:10.2307/1941990.

Liu, J., Shively, G., \& Binkley, J. (2013). Dietary diversity in urban and rural China: An endogenous variety approach. Paper presented at the Agricultural \& Applied Economics Association's 2013 AAEA \& CAES Joint Annual Meeting, Washington DC.

Lunduka, R., Ricker-Gilbert, J., \& Fisher, M. (2013). What are the farm-level impacts of Malawi's farm input subsidy program? A critical review. Agricultural Economics, 44(6), 563-579. doi:10.1111/agec.12074.

Mayer, A. M. B. (2014). Nutrition impact of agriculture and food systems: Malawi case study. Geneva: United Nations Standing Committe on Nutrition.

MINIAGRI. (2009). Strategic plan for agricultural transformation in Rwanda - Phase II (PSTA II). Kacyiru, Kigali, Rwanda: Rawanda Ministry of Agriculture and Animal Resources.

Ministry of Agriculture and Food Security (MoAFS) (2008). The 2007/ 2008 input subsidy programme review report. An internal review. Lilongwe, Malawi: MoAFS.

MNSO. (2012). Malawi Third Integrated Household Survey (IHS3) 2010-11 Basic Information Document. Zomba, Malawi: Malawi National Statistical Office.

Morgan, S. L., \& Harding, D. J. (2006). Matching estimators of causal effects - prospects and pitfalls in theory and practice. Sociological Methods \& Research, 35(1), 3-60. doi:10.1177/0049124106289164.

Orr, A. (2000). 'Green gold'?: Burley tobacco, smallholder agriculture, and poverty alleviation in Malawi. World Development, 28(2), 347363. doi:10.1016/s0305-750x(99)00127-8.

Rashid, D. A., Smith, L. C., \& Rahman, T. (2011). Determinants of dietary quality: evidence from Bangladesh. World Development, 39(12), 2221-2231. doi:10.1016/j.worlddev.2011.05.022.

Ricker-Gilbert, J., \& Jayne, T. S. (2011). What are the enduring effects of fertilizer subsidies on recipient households? (Staff Paper 2011-09). East Lansing, Michigan, USA: Michigan State University - Department of Agricultural Food and Resource Economics.

Ricker-Gilbert, J., Jayne, T. S., \& Chirwa, E. (2011b). Subsidies and crowding out: a double-hurdle model of fertilizer demand in Malawi. American Journal of Agricultural Economics, 93(1), 26 42. doi:10.1093/ajae/aaq122. 
Rosenbaum, P. R., \& Rubin, D. B. (1983). The central role of the propensity score in observational studies for causal effects. Biometrika, 70(1), 41-55. doi:10.1093/biomet/70.1.41.

Sahn, D. E. (1990). The impact of export crop production on nutritionalstatus in Ivory-Coast. World Development, 18(12), 1635-1653. doi: 10.1016/0305-750x(90)90060-b.

Sahn, D. E., Vanfrausum, Y., \& Shively, G. (1994). Modeling the nutritional and distributional effects of taxing export crops. Economic Development and Cultural Change, 42(4), 773-793. doi:10.1086/452120.

Savy, M., Martin-Prevel, Y., Traissac, P., Eymard-Duvernay, S., \& Delpeuch, F. (2006). Dietary diversity scores and nutritional status of women change during the seasonal food shortage in rural Burkina Faso. Journal of Nutrition, 136(10), 2625-2632.

Sianesi, B. (2004). An evaluation of the Swedish system of active labor market programs in the 1990s. Review of Economics and Statistics, 86(1), 133-155. doi:10.1162/003465304323023723.

Snapp, S., Kanyama-Phiri, G., Kamanga, B., Gilbert, R., \& Wellard, K. (2002). Farmer and researcher partnerships in Malawi: developing soil fertility technologies for the near-term and far-term. Experimental Agriculture, 38, 411-431. doi:10.1017/s0014479702000443.

Snapp, S. S., Blackie, M. J., Gilbert, R. A., Bezner-Kerr, R., \& Kanyama-Phiri, G. Y. (2010). Biodiversity can support a greener revolution in Africa. Proceedings of the National Academy of Sciences of the United States of America, 107(48), 20840-20845. doi:10.1073/pnas.1007199107.

Steele, K. A., Gyawali, S., Joshi, K. D., Shrestha, P., Sthapit, B. R., \& Witcombe, J. R. (2009). Has the introduction of modern rice varieties changed rice genetic diversity in a high-altitude region of Nepal? Field Crops Research, 113(1), 24-30. doi:10.1016/j.fcr.2009.04. 002

Swindale, A., \& Bilinsky, P. (2006). Household Dietary Diversity Score (HDDS) for Measurement of Household Food Access: Indicator Guide (Vol. 2). Washington, DC: Food and Nutrition Technical Assistance Project, FHI 360.

Theil, H., \& Finke, R. (1983). The consumer's demand for diversity. European Economic Review, 23(3), 395-400.

Thorne-Lyman, A. L., Valpiani, N., Sun, K., Semba, R. D., Klotz, C. L., Kraemer, K., et al. (2010). Household dietary diversity and food expenditures are closely linked in rural Bangladesh, increasing the risk of malnutrition due to the financial crisis. Journal of Nutrition, 140(1), 182S-188S. doi:10.3945/jn.109.110809.

Torheim, L. E., Ouattara, F., Diarra, M. M., Thiam, F. D., Barikmo, I., Hatloy, A., et al. (2004). Nutrient adequacy and dietary diversity in rural Mali: association and determinants. European Journal of Clinical Nutrition, 58(4), 594-604. doi:10.1038/sj.ejen.1601853.

UNWFP-VAM. (2006). Food consumption analysis technical guidance sheet: Calculation and use of the food consumption score in food security analysis. Rome: United Nations World Food Programme Vulnerability Analysis and Mapping.

Von Braun, J., \& Kennedy, E. T. (Eds.). (1994). Agricultural commercialization, economic development, and nutrition. Baltimore: International Food Policy Research Institute/The Johns Hopkins University Press.

White, H. (1980). A heteroskedasticity-consistent covariance matrix estimator and a direct test for heteroskedasticity. Econometrica, 48(4), 817-838.

Witcombe, J., Joshi, K. D., Virk, D. S., \& Sthapit, B. R. (2011). Impact of introduction of modern varieties on crop diversity. In J. M. Lenné \& D. Wood (Eds.), Agrobiodiversity management for food security: A critical review (pp. 87-98). Oxfordshire: $\mathrm{CAB}$ International.

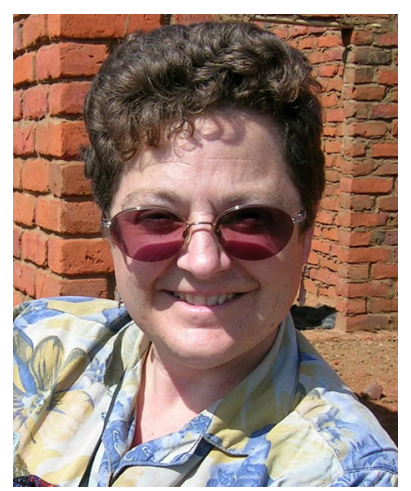

Sieglinde Snapp is a Professor at W.K. Kellogg Biological Station, Michigan State University. Sieglinde's research focuses on understanding the principles of resilient cropping system design and biologically-based soil management. This includes investigating the multi-functional role of accessory crops such as cover crops in mediating nutrient efficiency, soil function and healthy crop roots. A particular area of interest is the feedback loops in nitrogen and phosphorus availability mediated by plants and associated microbes. Predicting nutrient availability and tradeoffs between mineralization and assimilation processes are important questions her research group and collaborators address in organic and sustainable production systems. Sieglinde is committed to participatory research and extension approaches with iterative feedback from stakeholders. To this end, she developed the mother and baby trial design to link long-term research trials systematically with on-farm experimentation. Collaborations across social and biological scientists are essential in a rapidly changing world, and she works closely with multidisciplinary teams including scientists, farmers, students, advisors and extension educators to foster farmer innovation and build more sustainable, environmentally-friendly cropping systems. The participatory research methods and on-farm research trial designs she works on have been adopted by agronomists and plant breeders in 16 countries in Africa, Southeast Asia and in Paraguay.

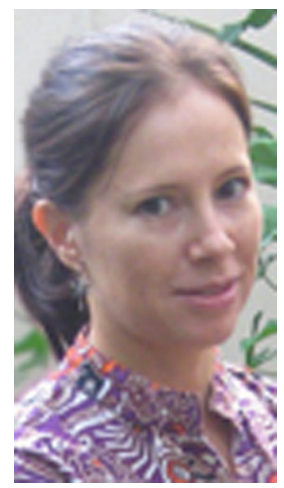

Monica Fisher is as an Adoption and Impact Assessment Economist at the International Maize and Wheat Improvement Center (CIMMYT). Prior to joining CIMMYT in 2012, Fisher was an Assistant Professor at Oregon State University and a Research Fellow and Team Leader of IFPRI's Malawi Strategy Support Program. She holds a PhD in agricultural economics from Purdue University, USA (2003). Fisher's research shares a geographical focus on sub-Saharan Africa and concerns a range of topics related to poverty, economic development, and the environment. Past research has used data she collected in Senegal and Malawi as well as large secondary datasets such as the Living Standards Measurement Study and the Demographic and Health Surveys. Fisher's research has been funded by the United States Agency for International Development, the US National Science Foundation, the US National Institutes of Health, the Brookings Institution, and Fulbright Hays. 